\title{
UN FORO DE DEBATE SOBRE EL SEGURO DE ENFERMEDAD: LAS CONFERENCIAS DEL ATENEO DE MADRID DE 1934*
}

\author{
M. ${ }^{\mathrm{a}}$ Isabel Porras Gallo \\ Profesora asociada de Historia de la Medicina - Unidad de Historia de la Medicina \\ Facultad de Medicina de Albacete - Univ. de Castilla-La Mancha \\ Edificio Benjamín Palencia. 02071 ALBACETE (España)
}

\section{RESUMEN}

En el presente trabajo, utilizando como fuente principal el contenido de las conferencias que el Ateneo de Madrid dedicó al Seguro de Enfermedad al inicio de 1934, se analiza una de las etapas del proceso negociador del Seguro Obligatorio de Enfermedad registrada en nuestro país. A través de dicho análisis se intentará mostrar cuáles eran las opiniones de los médicos sobre el Seguro Obligatorio de Enfermedad en esa fecha, y poner de relieve hasta qué punto éstas estaban influidas por las de sus colegas europeos. Se hará especial hincapié en detectar las diferencias y concomitancias con los profesionales alemanes y franceses, dado el peso que los modelos implantados en Alemania y Francia tuvieron a la hora de diseñar un plan de seguros sociales para nuestro país.

\section{SUMMARY}

This work studies one of the stages of the negotiating process of the State Health Care System in Spain, using the content of the «Ateneo de Madrid» conferences which held this subject at the beginning of 1934 as its prime source. It aims to show what the Spanish doctors' opinions were about the National Health Service at that time, and to highlight the influence of their European colleagues' views. It emphasizes on detecting the differences and concomitances with the German and French professionals, due to the influence that the models established in Germany and France had on the design of the Spanish National Health Service.

* Este trabajo se realiza en el marco del proyecto de investigación llevado a cabo como becaria postdoctoral del Ministerio de Educación y Ciencia en l'École des Hautes Études en Sciences Sociales de París. 


\section{INTRODUCCIÓN}

A la hora de hablar del siglo XX desde la perspectiva sanitaria, ha sido común reconocer como una de sus notas características la puesta en marcha de los diferentes sistemas de protección pública de la salud y la extensión de los que se habían iniciado con anterioridad. Tras lo acaecido en los últimos años, no cabe duda de que otro rasgo definitorio de dicha centuria son las sucesivas reformas neoliberales efectuadas desde que, con motivo de la crisis económica de 1973, se inició el cuestionamiento del modelo político-social denominado Estado de Bienestar ${ }^{1}$. En efecto, casi simultáneamente a la aparición de la crisis comenzó un debate sobre los distintos sistemas sanitarios colectivizados en buena parte del Mundo Occidental, que tuvo como una de sus primeras consecuencias la realización de reformas en dichos sistemas a finales de los setenta en algunos países y, sobre todo, en los años ochenta coincidiendo con una nueva manifestación del ciclo económico decenal ${ }^{2}$. El advenimiento de la crisis de los noventa propició la reactivación de dicho debate, que continúa abierto en el momento actual $^{3}$. De hecho, recientemente, algunas voces han recordado que las medidas adoptadas hasta ahora han estado presididas por fórmulas económicas de contención del gasto, y han insistido en la necesidad y urgencia de debatir ${ }^{4}$ y de

\footnotetext{
1 Una visión sintética sobre el surgimiento y configuración del Estado de Bienestar, figura en: GONZÁLEZ DE PABLO, A. (1992), «El surgimiento y conformación del Estado de Bienestar», Quirón, 23 (4), pp. 52-61. Un estudio más amplio sobre dicha cuestión referida a Gran Bretaña y Francia, y, en menor medida, a Alemania, Suecia y Estados Unidos, nos lo ofrece: ASHFORD, D.E. (1989), La aparición de los Estados de Bienestar, Madrid, Ministerio de Trabajo y Seguridad Social, Trad. esp. (1. ${ }^{a}$ ed. ingl., 1986). Más específicamente del caso de Francia, y desde una perspectiva del derecho, se ha ocupado EWALD, F. (1996), Histoire de l'État Providence, Paris, Grasset (1. ${ }^{\mathrm{a}}$ ed., 1986). Un análisis comparativo sobre las políticas de protección social de los países industrializados, se puede encontrar en: GORDON, M.S. (1990), La política de seguridad social en los países industrializados, Madrid, Ministerio de Tra-

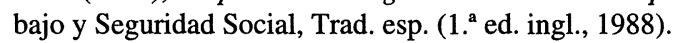

2 Sobre las repercusiones de la crisis económica en los sistemas sanitarios, puede verse la segunda parte del trabajo de MUÑOZ MACHADO, S. (1995), La formación y la crisis de los servicios sanitarios públicos, Madrid, Alianza Edit., pp. 129-159. De gran utilidad resulta la bibliografía que incluye en las pp. 172-176.

3 Uno de sus principales foros de expresión es la prensa general y la científico-profesional. Entre los numerosos artículos, cabe citar: ROMERO, F. (1996), «Los sistemas públicos de salud a debate», $E l$ Médico, 4-X-1996, pp. 20-24; G., J. (1996), «Jornadas sobre modernización de los sistemas públicos, organizada por The Economist, Arthur Andersen y Smithkline Beecham», Noticias médicas, 3268, Octubre 1996, pp. 12-18; «La Sanidad que quiere Aznar. Asistencia pública, gestión privada», Tiempo, 3-2-1997, pp. 52-61; el volumen de Esprit, de febrero de 1997 (La santé, à quel prix?), y el número 93 (enero-febrero de 1998) de la revista $M$ (La santé dans tous ses états: assistance, assurance ou droit universel).

4 GAUDILliÉRE, J.P. (1998), «La santé dans tous ses états: assistance, assurance ou droit universel», $M, 93$ (janv-févr. 1998), 5-6, p. 5.
} 
efectuar una reflexión adecuada sobre las posibles carencias presentes en las respectivas políticas de salud pública ${ }^{5}$.

En una situación como la descrita —marcada, en buena medida, por el temor de la población a que las reformas pendientes impliquen mayores recortes en las prestaciones, e incluso su desaparición - parece apropiado servirse de la reflexión histórica sobre el proceso de gestación de los distintos sistemas de salud pública para ofrecer una mejor perspectiva de dicha problemática, $y$, con ello, enriquecer el debate existente ${ }^{6}$. Es en este sentido en el que debe ser entendido el presente trabajo, que intenta contribuir a dicho fin mediante el análisis de una de las etapas del proceso negociador del Seguro Obligatorio de Enfermedad (SOE) registrada en nuestro país ${ }^{7}$. Concretamente, me refiero a la que tuvo lugar en los primeros meses de $1934^{8}$. Con tal

5 VIGARELLO, G. (1997), «La santé entre rationalité économique et rationalité sanitaire», Esprit, 2, 8-12, p. 10. En este sentido, conviene también recordar la inquietante extensión de las desigualdades frente a la enfermedad que, como muestran los datos epidemiológicos, han acompañado a las reformas efectuadas en el sistema sanitario de Gran Bretaña durante los 17 años de Gobierno conservador. PFEFFER, N. (1998), «Le Service national de santé britannique sous pression: management, privatisation et assistance», $M, 93,41-46$, p. 45.

6 Otra expresión de dicho debate han sido algunas monografías, como HUERTAS, R. \& MAESTRO, A. (coords.) (1991), La ofensiva neoliberal y la Sanidad pública, Madrid, FIM; DUMONT, J.P. (1993), Les systèmes de protection sociale en Europe, Paris, Économica; CASTEL, R. (1995), Les métamorphoses de la question sociale. Une chronique du salariat, Paris, Fayard; ROSANVALlON, P. (1995), La nouvelle question sociale: Repenser l'État providence, Paris, Seuil; MIZRAHI, A. et A. (1996), La protection sociale, Paris, La Découverte; y SKOCPOL, T. (1997), Boomerang: Health Care Reform and the Turn against Government, Norton.

7 Entre la bibliografía dedicada a este tema, cabe señalar: los trabajos de DANÓN BRETOS, J. (1988), «Sobre los inicios de la Seguridad Social en España»; y RODRíGUEZ OCAÑA, E.; ORTIZ GÓMEZ, T. (1988), «Los médicos españoles y la idea del seguro obligatorio de enfermedad durante el primer tercio del siglo XX», publicados todos ellos, respectivamente, en: VALERA, M.; EGEA, M.; y BLAZQUEZ, M D. (eds.), Libro de Actas. VIII Congreso Nacional de Historia de la Medicina. Murcia-Cartagena, 18-21 Diciembre 1986, Murcia, vol I, pp. 482-487; y pp. 488-501. Los realizados por CUESTA BUSTILLO, J. (1992), «Un punto de encuentro entre Medicina y trabajo: debates sobre el seguro de enfermedad, durante los años veinte, en España»; y MARTíNEZ QUINTERO, M. ${ }^{a}$ E. (1992), «Organizaciones obreras y patronales ante el seguro social de enfermedad»; publicados ambos, respectivamente, en: HUERTAS, R. y CAMPOS, R. (coords.), Medicina Social y clase obrera en España (Siglos XIX y XX), Madrid, FIM, t. I, pp. 321-347; y t. II, pp. 527-554. De esta cuestión también se han ocupado: MOLERO MESA, J. (1994), «Enfermedad y previsión social en España durante el primer franquismo (1936-1951). El frustado seguro obligatorio contra la tuberculosis», Dynamis, 14, pp. 199-225; HUERTAS GARCÍA-ALEJO, R. (1995), «La Sanidad nacional y el Seguro de Enfermedad». En: HUERTAS GARCÍA-ALEJO, R., Organización sanitaria y crisis social en España, Madrid, FIM, pp. 61-89; y PORRAS GALLO, M. ${ }^{\mathrm{a}}$ I. (1998a), «El camino hacia la instauración del Seguro obligatorio de enfermedad», El Médico, 679, pp. 70-77.

8 Del SOE durante la II República se han ocupado recientemente: JIMÉNEZ LUCENA, I. (1995), Cambio político y alternativas sanitarias: el debate sanitario en la II República, Málaga, Memoria doctoral inédita, pp. 158-181, 219-224, 246-257, y 298-324; PORRAS GALLO, M. ${ }^{\text {a }}$ I. (1998b), «Los médicos y la prensa frente al seguro de enfermedad en la primavera de 1934: una respuesta a la creación del Ministerio de Trabajo, Sanidad y Previsión». En: CASTEllanOS, J.; JiMÉNEZ LuCENA, I.; RUIZ SOMA- 
propósito, me planteo como objetivos mostrar, a través del contenido de las conferencias celebradas en el citado año en el Ateneo de Madrid sobre el Seguro de Enfermedad, cuáles eran las opiniones de los médicos españoles sobre el SOE, y poner de relieve hasta qué punto éstas estaban influidas por las de sus colegas europeos 9 . Haré especial hincapié en detectar las diferencias y concomitancias con los profesionales alemanes y franceses. Esta decisión ha venido marcada, por un lado, por la tradición y el peso del modelo alemán - referente por excelencia a la hora de instaurar los seguros sociales en la mayoría de los países europeos-; y, por otro, por los puntos en común que, según J. Cuesta y E. López, existieron en el proceso de gestación de los seguros sociales en España y Francia, y la atención que desde nuestro país se prestó al modelo francés ${ }^{10}$.

\section{EL SEGURO DE ENFERMEDAD EN ESPAÑA CON ANTERIORIDAD A LA II REPÚBLICA}

Muy brevemente, y para contextualizar el contenido del trabajo, conviene recordar que la colectivización de la asistencia médica se inició en los últimos años de la pasada centuria. El primer paso dado en este sentido se produjo en Alemania en 1883 con la creación por Bismarck del denominado sistema de las Krankenkassen. Este modelo fue adoptado por varios países europeos en los años del tránsito del siglo XIX al XX, completándose el proceso de instauración de una asistencia sanitaria colectivizada en el período de entreguerras y, sobre todo, al término de la Segunda Guerra Mundial ${ }^{11}$.

VILLA, M. ${ }^{\text {a }}$ J. \& GARDETA, P., La Medicina en el siglo XX. Estudios históricos sobre Medicina, Sociedad y Estado, Málaga, Sociedad Española de Historia de la Medicina, pp. 183-192; y PORRAS GALlo, M. ${ }^{a}$ I. (1998c), «El Seguro de Enfermedad en la II República española: del decreto del 25 de diciembre de 1933 al I Congreso Nacional de Sanidad». En: CASTILLO, S. y ORTIZ DE ORRUÑO, J. M. a (coords.), Estado, protesta y movimientos sociales, Bilbao, Asociación de Historia Social, Universidad del País Vasco, pp. 171-176.

${ }^{9}$ El contenido de las conferencias aparece recogido en: ATENEO DE MADRID (1934), El Seguro de Enfermedad y los Médicos Españoles. Ciclo de conferencias organizado por la Sección de Ciencias Médicas, Madrid, Unión Poligráfica. El resto de las fuentes y de la bibliografía consultada para la elaboración del presente trabajo, se irán citando a lo largo del texto.

10 Cuesta Bustillo, J. \& LÓPEZ CAMPILlO, E. (1990), «L'Espagne devant le modèle français d'assurances sociales». En: Colloque sur l'histoire de la Sécurité social (Paris, 1989), Paris, A.E.H.S.S., pp. 73-91.

11. Información sintética sobre el proceso de implantación de los sistemas sanitarios colectivizados en los diferentes países, figura en: LÓPEZ PIÑERO, J.M. ${ }^{a}$ (1978), «La colectivización de la asistencia médica: una introducción histórica». En: DE MIGUEL, J.M. (comp.), Planificación y reforma sanitaria, Madrid, C.I.S., pp. 21-47; y PESET, J.L. (1978), «Capitalismo y medicina: ensayo sobre el nacimiento de la seguridad social», Estudios de Historia Social, 7, pp. 185-216. Sobre el caso francés sigue siendo tremendamente ilustrativo el ya clásico trabajo de HATZFELD, H. (1971), Du paupérisme à la Sécurité Sociale, Paris, Libr. A. Colin [Esta obra fue editada nuevamente en 1989 por Presses Universitaires de Nancy]. 


\section{UN FORO DE DEBATE SOBRE EL SEGURO DE ENFERMEDAD:}

Por lo que se refiere a nuestro país, es preciso señalar que el proceso negociador relativo al establecimiento del SOE, que concluyó en 1944 con la efectiva puesta en marcha de dicho seguro, fue bastante largo, y estuvo marcado en muy buena medida por la labor desarrollada por los técnicos del Instituto Nacional de Previsión (INP) ${ }^{12}$, los médicos higienistas con inquietudes médico-sociales y las organizaciones obreras.

Aunque desde el inicio del siglo XX los seguros sociales fueron considerados medios adecuados para solucionar algunos de los problemas que en el ámbito sanitario presentaba nuestro país ${ }^{13}$, no fue hasta 1917 cuando estos elementos alcanzaron verdadero protagonismo ${ }^{14}$. En efecto, la celebración en junio de ese año del II Congreso Nacional de Economía en Madrid ${ }^{15}$ y, en el mes de octubre, de la Primera Conferencia de Seguros sociales, pusieron de relieve la necesidad de defender su obligatoriedad y de instaurarlos ${ }^{16}$. Con tal propósito se convocaron las Conferencias de Bilbao (1921) y Barcelona (1922). En esta última, se produjo un primer intento de

\footnotetext{
12 Sobre los orígenes y el papel desarrollado por el INP en el ámbito de la previsión social española, pueden consultarse: MONTERO GARCÍA, F. (1988), Orígenes y antecedentes de la previsión social, Madrid, Ministerio de Trabajo y Seguridad Social; CUESTA BUSTILLO, J. (1988), Hacia los seguros sociales obligatorios. La crisis de la Restauración, Madrid, Ministerio de Trabajo y Seguridad Social; y SAMANIEGO BONEU, M. (1988), La unificación de los seguros sociales a debate. La Segunda República, Madrid, Ministerio de Trabajo y Seguridad Social. Información sobre esta cuetión figura también en varios de los trabajos que forman parte del volumen colectivo De la Beneficencia al bienestar social. Cuatro siglos de acción social, 1986, Madrid, Siglo XXI.

${ }^{13} \mathrm{El} \mathrm{SOE}$ y los seguros sociales fueron considerados como importantes medios de lucha contra la tuberculosis en los Congresos sobre dicha enfermedad de 1908, 1910 y 1912. MOLERO MESA, J.; RODRÍGUEZ OCAÑA, E. (1988), «Tuberculosis y previsión. Influencia de la enfermedad social modelo en el desarrollo de las ideas médicas españolas sobre el seguro de enfermedad». En: VALERA, M.; EGEA,

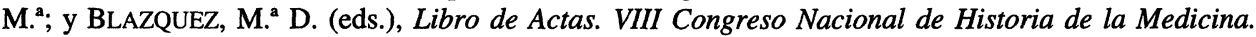
Murcia-Cartagena, 18-21 Diciembre 1986, Murcia, vol I, pp. 503-505. A su vez, para Martín Salazar eran élementos primordiales para lograr nuestra redención sanitaria. MARTín SALAZAR, M. (1913), La Sanidad en España, Madrid, impr. Coleg. Nacional de sordomudos y ciegos, pp. 49-51.

14 MARTÍNEZ QUINTEIRO, E. (1988), «La crisis de 1917 y la reorganización de los seguros». En: MONTERO GARCíA, F., Orígenes y antecedentes de la previsión social, Madrid, Ministerio de Trabajo y Seguridad Social, pp. 326-330; y MARTíNEZ QUINTEIRO, E. (1990), «El nacimiento de los seguros sociales, 1900-1918». En: Historia de la Acción social Pública en España. Beneficencia y Previsión, Madrid, Ministerio de Asuntos Sociales, 241-286, pp. 277-281. El protagonismo alcanzado por los seguros sociales permitió que, entre 1919 y 1922, fueran considerados como elementos apropiados para la profilaxis pública de las enfermedades infecciosas. PORRAS GALLO, M. ${ }^{a}$ I. (1993), «La profilaxis de las enfermedades infecciosas tras la pandemia gripal de 1918-19: los seguros sociales», Dynamis, 13, pp. 279293; PORRAS GALLO, M. ${ }^{2}$ I. (1994), «La lucha contra las enfermdedades 'evitables' en España y la pandemia de gripe de 1918-19», Dynamis, 14, pp. 159-183.

15 Sobre el contenido de dicho Congreso, véase: II Congreso de Economía Nacional, celebrado de Madrid durante los días 2 al 10 de junio de 1917: Resumen de los trabajos del Congreso, Madrid, V. Rico.

16 «Conferencia de Seguros Sociales. Documento n. ${ }^{\circ} 20 »$. En: Conferencia de Seguros Sociales celebrada en Madrid en los días 24 a 31 de octubre de 1917, 1917, Madrid, Sobrinos de la sucesora de M. Minuesa de los Ríos, pp. 117-119.
} 
iniciar dicha instauración. A tal objeto, el INP presentó un proyecto unificado de seguros sociales, inspirado en el modelo alemán, y muy similar al que, por esas fechas, se estaba discutiendo en Francia ${ }^{17}$ que, especialmente en lo relativo al $\mathrm{SOE}^{18}$, no tuvo buena acogida. De hecho, existieron profundas disensiones entre la clase médica, pudiéndose hablar básicamente de dos posturas diferentes. Por un lado, la de los higienistas, técnicos del INP y médicos socialistas, defensores de la inmediata implantación del SOE; y, por otro, la del resto del colectivo médico que, congregado en torno a diversas organizaciones y con razones y objetivos distintos, se oponía a su puesta en marcha. Mientras los médicos titulares proponían la nacionalización del ejercicio médico, los Colegios profesionales y sindicatos defendieron la práctica liberal, cuestionando el derecho del asegurado a recibir atención médica como una de las prestaciones, y reclamando la libertad de elección de facultativo, el cobro directo a los pacientes por acto médico, así como su intervención en la regulación de la asistencia sanitaria proporcionada por el $\mathrm{SOE}^{19}$.

La constatación de la fuerte oposición de la profesión médica frente al SOE motivó que, tras la Conferencia de Barcelona, la idea de su instauración se abandonara, permaneciendo en dicha situación durante la dictadura de Primo de Rivera ${ }^{20}$.

\section{El SEGURO DE ENFERMEDAD EN EL ATENEO DE MADRID AL INICIO DEL BIENIO NEGRO REPUBLICANO}

Con el establecimiento de la II República se produjo un cambio de actitud frente a los seguros sociales y al SOE. En el artículo 46 de la nueva Constitución se reconoció al trabajo como obligación social y subsidiario de la protección de las leyes, contemplándose que la legislación social regularía, entre otras cuestiones, el seguro de enfermedad. Respondiendo a este espíritu e influido por el peso que a nivel internacional habían adquirido los seguros sociales, el Gobierno ratificó en 1932 los acuerdos de la Conferencia Internacional del Trabajo de 1927, relativos al establecimiento del SOE

${ }^{17}$ Sobre las similitudes y diferencias existentes entre el proyecto francés presentado al Parlamento en 1920, y el preparado en España con motivo de la Conferencia de Barcelona, véase: CUESTA BUSTILLO, J. \& LÓPEZ CAMPILLO, E. (1990), pp. 77-82.

18 Para mayor información sobre esta Conferencia, véase: INP (1925), Conferencia Nacional de Seguros de Enfermedad, Invalidez y Maternidad. Barcelona, noviembre de 1922. I. Ponencias, actas y conclusiones. II. Documentos de información, Madrid, Sobrinos de la Sucesora de M. Minuesa, 2 vols.

19 INP (1925), vol. I, pp. 251-294.

20 No obstante, el tema no estaba olvidado totalmente, como lo muestra el hecho de que el texto de la Ley francesa sobre los seguros sociales de 1928 fuera reproducido casi inmediatamente en el Boletín analítico de la Secretaría de la Cámara de Diputados (n..$^{\circ}$, pp. 9-35; y n. ${ }^{\circ}$ 5, pp. 230-248), y el seguimiento que se hizo desde nuestro país del debate francés sobre la gestación, aprobación y aplicación de dicha ley. Cuesta Bustillo, J. \& LóPEz CAMPILlo, E. (1990), pp. 75, y 87-89. 
para los trabajadores asalariados de la industria, del comercio, del servicio doméstico y de la agricultura. De cara a materializar los acuerdos suscritos, el ministro de Trabajo y Previsión, Francisco Largo Caballero, por Orden de 10 de mayo de 1932, encargó al INP el establecimiento de un sistema completo de seguros sociales unificado ${ }^{21}$.

Con el fin de responder al cometido recibido, el INP constituyó una Ponencia nacional $^{22}$ que, en las fechas en las que se celebraron las Conferencias del Ateneo madrileño analizadas en este trabajo, continuaba elaborando el proyecto de ley que hiciera realidad dicho encargo. Desde el citado Instituto se estaba diseñando un modelo de SOE, semejante al alemán, que no era bien visto por buena parte de la clase médica, pero que había contado con el apoyo del Gobierno republicano durante el bienio azañista-socialista ${ }^{23}$, así como con el de la mayor parte del sector conservador. Ésta era la situación cuando, tras las elecciones de noviembre de 1933, se produjo el ascenso de los radicales y la CEDA al poder, y el SOE cobró renovada actualidad. La razón de ello fue el decreto de 25 de diciembre de 1933, una de las primeras medidas tomadas por el nuevo titular del Ministerio de Trabajo y Previsión Social, el médico radical Estadella. En virtud de dicho decreto, los servicios, cargos y deberes que dependían de la subsecretaría de Sanidad y Beneficencia, adscrita al Ministerio de la Gobernación, pasaban a depender del Ministerio de Trabajo, Sanidad y Previsión.

El traspaso de Sanidad al Ministerio de Trabajo y la inclusión de Sanidad y Previsión en una misma subsecretaría, unido al protagonismo adquirido por el grupo de personas al que me referiré como clase médica organizada ${ }^{24}$ en el nuevo Gobierno,

${ }^{21}$ De las actuaciones de la II República en materia de Medicina Social se han ocupado: DANÓN BRETOS, J. (1988), pp. 485-487; RODRíGUEZ OCAÑA, E. y MENÉNDEZ NAVARRO, A. (1988), «Objetivos y estructura de la Medicina Social en la II República. El primer Congreso Nacional de Sanidad». En: VALERA, M. y BLÁZQUeZ, M.D. (eds.), Actas del VIII Congreso Nacional de Historia de la Medicina. Murcia-Cartagena, 18-21 de diciembre de 1986, Murcia, vol. I, pp. 514-523; RODRÍGUEZ OCAÑA, E. y ORTíZ GÓMEZ, T. (1988), pp. 494-497; RODRÍGUEZ OCAÑA, E. (1990), «La asistencia médica colectiva en España hasta 1936». En: ÁlVAREZ JunCO, J. (coord.), Historia de la Acción Social Pública en España. Beneficencia y Previsión, Madrid, Ministerio de Asuntos Sociales, 321-359, pp. 354-355; HUERTAS GARCÍA-ALEJO, R. (1995), pp. 74-82; JIMÉNEZ LUCENA, I. (1995), pp. 158-192; 219-224; 246-257 y 298-325. Recientemente esta última autora ha analizado la posición de los médicos frente a la intervención estatal en la actividad médico-sanitaria. JIMÉNEZ LUCENA, I. (1997), «El Estado como aliado. Los médicos y el proceso de estatalización de los servicios sanitarios en la Segunda República española», Asclepio, 49 (1), pp. 193-216.

22 Entre los integrantes de dicha Ponencia figuraron los médicos: Palanca, R. Morote, Bardají, Espinosa, Pascua, Pérez Mateos, Piga, García Tornel, G. Ossorio, Dacio Crespo Álvarez, Laffon, Sanz Barrio, G. Salvo, etc. ATENEO DE MADRID (1934), p. 203. Como veremos posteriormente, la mayoría de los autores citados fueron convocados para tomar parte en las Conferencias objeto de este estudio.

23. Sin embargo, como puso de relieve el Congreso ordinario de la UGT de 1932, en las filas socialistas no existía unanimidad en cuanto al tipo de sistema público de protección de la salud a implantar. «XVII Congreso de la Unión general de trabajadores», El Socialista, 17 de octubre de 1932. «XVII Congreso de la Unión general de trabajadores», Anales del INP, 24 (99), (1932), pp. 697-700.

${ }^{24}$ Bajo estos términos se incluyen los Colegios de médicos y las distintas asociaciones médicas. 
presidido por Alejandro Lerroux, se relacionó con posibles cambios en la organización, aplicación y control del SOE. Esto produjo la inquietud de los médicos y del INP, que temió la pérdida de protagonismo ${ }^{25}$. De ahí la discusión que a lo largo del primer trimestre de 1934 se suscitó, tanto sobre el traspaso de Sanidad al Ministerio de Trabajo como sobre el SOE. Uno de los principales foros de expresión de dicho debate, especialmente en lo que se refiere al último punto, fueron las Conferencias del Ateneo de Madrid.

En efecto, la Sección de Medicina del Ateneo madrileño decidió consagrar las sesiones del nuevo curso al Seguro de Enfermedad. Con ello, según señalaba su presidente Sánchez Covisa, se ofrecía un «campo neutral» de discusión, en el que conferenciantes pertenecientes a los «más diversos campos sociales y políticos» pudieran presentar al auditorio «toda clase de opiniones» sobre el SOE ${ }^{26}$. Sin embargo, no parece tampoco desacertado pensar que con esta iniciativa, que se desarrolló entre el 19 de enero y el 9 de marzo de 1934, se disponía de una buena oportunidad para alcanzar un fin primordial: vencer las reservas de los médicos frente al SOE y, más concretamente, respecto al modelo que se estaba gestando en el INP. Es quizás por eso por lo que más de la mitad de los convocados se hallaban comprometidos en mayor o menor medida en la defensa del tipo de seguro diseñado desde el citado Instituto $^{27}$. En efecto, además de representantes de la clase médica organizada, como Antonio Piga - Presidente del Colegio de Médicos de Madrid-, Francisco Ruiz Morote - Inspector provincial de Sanidad y Presidente del Colegio de Médicos de Cáceres ${ }^{28}$ - y Antonio Ossorio - Presidente de la Asociación Oficial de Inspectores Municipales de Sanidad y Médicos Titulares de España-, intervinieron cinco expositores más que pertenecían al INP o estaban muy implicados en la tarea realizada desde dicha institución. Concretamente, entre quienes formaban parte del INP en calidad de técnicos, se contaban Severino Aznar — presidente de la Subponencia del Seguro de Enfermedad, y perteneciente a la corriente ideológica del catolicismo social-y los médicos Joaquín Espinosa - Profesor de Medicina Social en la Escuela Nacional de Sanidad, y de la misma corriente ideológica que el anterior- y Torre Blanco - afiliado del Sindicato de la Unión General de Trabajadores-. A los anteriores hay que añadir el médico socialista Marcelino Pascua - presidente de una de

\footnotetext{
${ }^{25}$ Mayor información sobre esta cuestión, puede encontrarse en: PORRAS GALLO, M. ${ }^{\mathrm{a}}$ I. (1998b).

${ }^{26}$ ATENEO DE MADRID (1934), pp. 6 y 7.

27 Entre los convocados hubo también algunas ausencias, como las de Pérez Mateos, médico artífice de la Mutualidad de Previsión Médica, Subsecretario de Sanidad y Previsión, y presidente de una de las 7 Comisiones específicas creadas por la Subponencia del Seguro de Enfermedad para poner en marcha el SOE [SAMANIEGO BONEU, (1988), p. 356.]; Carlos González Posada; y Enrique Bardají, Inspector provincial de Sanidad de Madrid y miembro de la subponencia del SOE. ATENEO DE MADRID (1934), p. 7.

28 Este médico, que tuvo un papel destacado en el proceso de modernización sanitaria de nuestro país, fue becario de la Fundación Rockefeller en Estados Unidos durante los años 1927 y 1928. Información facilitada por Esteban Rodríguez Ocaña.
} 
las siete Comisiones específicas creadas por la Subponencia del $\mathrm{SOE}^{29}$-, y el miembro del partido reformista Gustavo Pittaluga -integrante de la Subponencia del Seguro de Enfermedad ${ }^{30}$-, ambos artífices destacados de la modernización sanitaria que se estaba acometiendo en nuestro país ${ }^{31}$.

Como vemos, entre los ponentes cabe reseñar también algunas ausencias significativas, como la de los médicos pertenecientes a la $\mathrm{CNT}^{32}$, o la de los socialistas partidarios de modelos de SOE menos conservadores. De haber contado con su presencia, dispondríamos indudablemente de un panorama más completo de las posiciones mantenidas por el colectivo médico. A pesar de ello, como mostrarán las próximas páginas, el análisis del contenido de las Conferencias del Ateneo de Madrid proporciona una interesante información sobre las principales ideas de buena parte de la clase médica española frente al SOE al inicio del bienio negro republicano, y revela los diferentes puntos de fricción.

\section{BAJO EL FANTASMA DE LA SOCIALIZACIÓN DE LA MEDICINA}

A tenor de lo expuesto hasta ahora resulta evidente que la opinión favorable y firmemente decidida a la implantación del SOE no era plenamente compartida por la

${ }^{29}$ SAMANIEgo Boneu, (1988), p. 356. Una importante aportación de Pascua, de cara al diseño del SOE, fue su libro: INP (1935), Morbilidades globales. ClAVERO GONZÁLEZ, G. (1992), «La obra de Marcelino Pascua en su entorno». En: I Encuentro Marcelino Pascua. Estadísticas DemográficoSanitarias, Madrid, Ministerio de Sanidad y Consumo, Instituto de Salud Carlos III, 17-23, p. 20. Desde su posición como jefe de los Servicios de Estadística Sanitaria de la Dirección General de Sanidad durante los años 1929/31 y 1933/36, y como Director General de Sanidad entre 1931 y 1933, supo impulsar toda una amplia reforma de la Sanidad Pública. BERNABEU MESTRE, J. (1992), «Marcelino Pascua desde la perspectiva histórica». En: I Encuentro Marcelino Pascua. Estadísticas Demográfico-Sanitarias, Madrid, Ministerio de Sanidad y Consumo, Instituto de Salud Carlos III, 11-15, p. 12.

${ }^{30}$ Fue Director de la Escuela Nacional de Sanidad desde 1929 hasta su exilio al final de la Guerra civil, y estuvo muy ligado a las iniciativas de la Fundación Rockefeller. Una visión bastante completa sobre este autor, figura en la tesis doctoral de MARTín GómEZ, S. (1987), Vida y obra de Don Gustavo Pittaluga Fattorini, Facultad de Medicina, Universidad Complutense de Madrid.

${ }^{31}$ Recientemente, en el marco del estudio del papel de la Fundación Rockefeller en la modernización científico-sanitaria de nuestro país, se han puesto de relieve las importantes contribuciones que realizaron en este sentido Marcelino Pascua, Gustavo Pittaluga y Ruiz Morote. Cfr. RODRíGUEZ OCAÑA, E.; BERNABEU MESTRE, J.; BARONA, J.L. (1998), «La Fundación Rockfeller y España, 1914-1939. Un acuerdo para la modernización científica y sanitaria». En: VI Congreso de la S.E.H.C.Y.T., septiembre 1996, Segovia, (e.p.); y RODRÍGUEZ OCAÑA, E. (1998), «La intervención de la Fundación Rockfeller en la creación de la sanidad contemporánea en España». En: VI Jornadas Marcelino Pascua, Madrid, junio de 1997, (e.p., $\mathrm{n} \square$ especial de Revista de Sanidad de Higiene Pública).

${ }^{32}$ La corriente anarco-sindicalista juzgaba limitado e insuficiente el modelo que se estaba preparando. POLO FIAYO, F. (1933), «Problemas urgentes. Municipalización de la Asistencia Pública», El Socialista, 7 de enero de 1933. 


\section{M. ${ }^{a}$ ISABEL PORRAS GALLO}

clase médica española. En efecto, tan sólo una minoría reformista participaba de dicho entusiasmo. El resto, tal y como reconocieron algunos de los conferenciantes, mantenía una actitud que iba desde la indiferencia o la simple desorientación hasta la oposición, habiéndose iniciado incluso una campaña propagandística contra dicha medida en algunas revistas médicas ${ }^{33}$. De hecho, Ossorio, Piga, Torre Blanco y Severino Aznar coincidieron en señalar que la mayoría de los médicos, y de modo particular los titulares, se hallaban inquietos, recelosos y expectantes ${ }^{34}$. Este modo de reaccionar no era nada novedoso. Como he indicado anteriormente, algo similar había ocurrido en la Conferencia de Barcelona de 1922. Un comportamiento parecido se había observado también en varios países de nuestro entorno, destacando especialmente la hostilidad mostrada por los facultativos franceses desde el mismo momento en que se inició la elaboración del proyecto de ley sobre los Seguros sociales al término de la Primera Guerra Mundial ${ }^{35}$.

A la hora de intentar buscar razones que permitan justificar esa actitud, es preciso considerar que para la clase médica, uno de los riesgos, quizás el principal, que entrañaba la implantación del SOE, era el de la socialización de la Medicina y, con ello, la desaparición, o, al menos, la limitación del ejercicio liberal. Este punto fue apuntado, entre otros, por Piga y Torre Blanco ${ }^{36}$. Sin duda, por un lado, el hecho de que en la Unión Soviética y en algún otro país del Este de Europa la puesta en marcha de los seguros sociales se hubiera acompañado de la funcionarización de los médicos y,

${ }^{33}$ En relación con esta cuestión, véanse las opiniones de Marcelino Pascua, Ruiz Morote, Torre Blanco, Pittaluga y Severino Aznar. ATENEO DE MADRID (1934), pp. 96, 118, 181-182, 225-226 y 342-354.

34 ATENEO DE MADRID (1934), pp. 133, 159, 163, 176, 200, 286-287 y 319-322.

${ }_{35}$ Los facultativos franceses se mostraron recelosos e inquietos desde el mismo momento en que comenzó a elaborarse el proyecto de ley sobre los Seguros sociales, e iniciaron una campaña en las revistas científico-profesionales que se fue intensificando a lo largo de los aproximadamente diez años que duró el proceso de gestación y puesta en marcha de los Seguros sociales en el vecino país. Una pequeña muestra de la abundante y temprana bibliografía aparecida, en la que se pone de relieve esa actitud, e incluso su oposición frente al SOE, es: DESFOSSES, P. (1920), «L'assurance-maladie», La Presse Médicale, 96, p. 1756; D.P. (1921), «L'assurance-invalidité-maladie», La Presse Médicale, 4, p. 51; BoudIN, P. (1921), «L'assurance-maladie», La Presse Médicale, 12, pp. 198-200; ACADÉMIE DE MÉDECINE (1924), «À propos de l'assurance-maladie», La Presse Médicale, 98, p. 978; ACADÉMIE DE MÉDECINE (1925), «La loi sur les assurances sociales», La Presse Médicale, 27, p. 438; ACADÉMIE DE MÉDECINE (1925), «La loi sur les assurances sociales», La Presse Médicale, 35, p. 573. El inicio del debate parlamentario sobre el proyecto de ley relativo a los Seguros sociales franceses dio también lugar a la confección de varias tesis al inicio de los años veinte. Estas tesis fueron realizadas tanto desde el ámbito de la Medicina como desde otros campos (derecho, economía, sociología, etc.). Entre las primeras, claramente opuesta a dicho proyecto, cabe citar: LAVERSIN, M. (1923), Les lois modernes d'assurances sociales considérées des points de vue biologique et médical, Paris, L'expansion scientifique française, $113 \mathrm{pp}$. Un sentido totalmente distinto tuvo la tesis realizada, para la obtención del doctorado en Sociología, por el también médico francés: EYLAUD, J.-M. (1929), Les Assurances Sociales en France et la protection de la santé publique, Thèse du doctorat en Sociologie (Genève).

36 ATENEO DE MADRID (1934), pp. 175 y 186-187. 
por otro, el papel destacado que los socialistas estaban teniendo en nuestro país de cara a la instauración del $\mathrm{SOE}^{37}$, habían contribuido a que, como indicaron Marcelino Pascua, Pittaluga y Severino Aznar, se considerase el SOE como una obra socialista, e incluso como una imposición del Partido Socialista ${ }^{38}$. Algunas voces se habían alzado igualmente en esa misma dirección en Francia ${ }^{39}$. Es cierto que en ambos países los seguros sociales habían contado, y contaban, con el apoyo de los socialistas, pero también, como indicó Aznar, con el de la Democracia Cristiana ${ }^{40}$.

Incluso, aunque no se llegara a una completa socialización de la Medicina, la clase médica se mostraba inquieta por las modificaciones que se producirían en su actividad profesional como consecuencia de la instauración del SOE. En este sentido, el problema más grave, según el presidente del Colegio de Médicos de Cáceres Ruiz Morote, era el que la organización de la asistencia médica pasara a manos distintas de los profesionales de la Medicina ${ }^{41}$. Junto a esta pérdida de protagonismo del colectivo médico, Piga llamó la atención sobre el deterioro de la labor desarrollada por el facultativo como consecuencia de hallarse bajo el efecto de unos honorarios bajos y de un trabajo agotador, que le impediría disponer de tiempo para la lectura, la formación continuada y la impartición de conferencias ${ }^{42}$. Además, según el presidente del Colegio de Médicos de Madrid, el SOE comprometería asimismo la economía nacional por cuanto entrañaría prestaciones superfluas, una burocracia exagerada y costosa y, sobre todo, al no existir el seguro de paro, podría ser utilizado como remedio de las situaciones generadas por la ausencia de trabajo ${ }^{43}$. Sin embargo, teniendo en cuenta los fines socio-sanitarios del SOE, Ruiz Morote echaba en falta una cobertura total y la concesión de un mayor peso a la prevención de la enfermedad frente al predominio de la medicina curativa ${ }^{44}$.

La mayoría de los inconvenientes señalados por la clase médica española, que acabo de enunciar, figuraban en el libro del alemán $\operatorname{Liek}^{45}$, y habían sido recogidos

\footnotetext{
37 En Francia, los socialistas habían tenido también un papel muy destacado, tal y como reconocía Georges Buisson, secretario adjunto de la C.G.T. Buisson, G. (s.a.), C.G.T. Pour connaître les Assurances Sociales, Paris, Éd. C.G.T., p. 3.

38 ATENEO DE MADRID (1934), pp. 56, 226, y 320-321.

39 Varios fueron los autores que se manifestaron en este sentido. Entre ellos, el médico católico François Guermonprez. GUERMONPREZ, Fr. (1933), «Les Assurance sociales fallacieuses et inhumaines», Bulletin de la société médicale de S. Luc, S. Côme, S. Damien, 1, 26-28, p. 27.

40. ATENEO DE MADRID (1934), p. 322. Una idea acerca del importante papel representado por los católicos-sociales franceses en la gestación y aplicación de la ley sobre los seguros sociales, puede obtenerse en: TESSIER, G. (1929), En face des assurances sociales, Paris, Éd. Spes.

41 ATENEO DE MADRID (1934), pp. 120-121.

42 ATENEO DE MADRID (1934), pp. 169-170.

43 ATENEO DE MADRID (1934), pp. 168-177.

44 ATENEO DE MADRID (1934), pp. 119-120.

45 LIEK, E. (1929), Les méfaits des assurances sociales en Allemagne et les moyens d'y remédier, trad. française, Paris, Payot, pp. 59-70.
} 
esquemáticamente en el texto de Espinosa ${ }^{46}$. En términos similares o, en ocasiones, más duramente, se habían expresado en Francia varios autores ${ }^{47}$. Estas coincidencias no nos deben extrañar, sobre todo si tenemos en cuenta que el proceso de gestación y puesta en marcha de la ley francesa sobre los Seguros sociales fue seguido con vivo interés desde nuestro país ${ }^{48}$. Ni el INP ni el colectivo médico permanecieron ajenos a las reacciones que se suscitaron en los distintos sectores de la sociedad francesa, y mucho menos a la lucha llevada a cabo por la clase médica. A lo largo de los años, se estuvo muy atento a las ideas vertidas en la abundante literatura que proporcionaron los médicos galos, así como a las contenidas en las traducciones que se efectuaron de algunas obras alemanas, belgas o suizas ${ }^{49}$.

\section{LA IMPLANTACIÓN DEL SEGURO OBLIGATORIO DE ENFERMEDAD: UNA OBLIGACIÓN Y UN MEDIO PARA MEJORAR LA SANIDAD}

Sin embargo, pese a admitir ciertos efectos negativos del SOE, derivados según algunos autores de una legislación o una aplicación defectuosas ${ }^{50}$, se le reconocían

46 ESPINOSA FERRANDIZ, J. (1933), El Seguro de Enfermedad. Estudio médico-social ante su implantación en España, Madrid, Biblioteca de la Revista «Medicina», pp. 44-45.

${ }^{47}$ Entre ellos cabe citar los siguientes: GUERMONPREZ, Fr. (1928), Assurances sociales. Études médicales autour de la loi 5 Avril 1928, Paris, Amédé Legrand édit., pp. 24-25, y 37-40; GUERIN, P. (1929), L'État contre le médecin. Vers une renaissance corporative, Paris, Éd. Médicales Norbert Maloine, 2. ${ }^{a}$ éd. (1. ${ }^{a}$ éd. Décembre 1928), pp. 1-51; LAVERsin, M. (1923), pp. 32-35, y 43-113; BUGIEL, V. (1930), «La lutte du Corps médical contre les Assurances sociales du Reich», La Presse Médicale, 30, p. 508; Desfosses, P. (1929a), «Où en est la question des Assurances sociales?», La Presse médicale, 24, p. 397; D., P. (1925), «La question des Assurances sociales», La Presse médicale, 38, p. 637; D., P. (1929b), «Livres Nouveaux. Les méfaits des Assurances sociales en Alemagne et les moyens d'y remédier, par le Dr. E. Liek», La Presse médicale, 24, p. 398; y D., P. (1929c), «Les conséquences médicales du fonctionnement de la loi allemande des Assurances sociales», La Presse médicale, 91, pp. 1487-1488; DESTOUCHES, L.F. (1928), «Les Assurances sociales et une politique économique de la santé publique», La Presse médicale, 94, pp. 1499-1501; SPECKLIN, «Les répercusions des Assurances sociales sur l'exercice de la Médecine», La Presse médicale, 5, pp. 78-79; y SPECKLIN, «Considérations critiques sur les Assurances sociales. Une solution nouvelle: l'épargne individuelle obligatoire», La Presse médicale, 19, pp. 305-310; y WEISS, G. (1929), «Une lettre du professeur Weiss à propos des Assurances sociales», La Presse médicale, 100, p. 1633.

48 Cuesta Bustillo, J. \& LóPez Campillo, E. (1990), pp. 73-91.

49 De hecho, algunas de las obras citadas (Liek, Goldman \& Grotjahn, Chauveau y Tessier) y las que el belga René Sand dedicó a abordar los temas de protección social, forman parte de los fondos de la Biblioteca del INSALUD y, de forma más escasa, de los de la Biblioteca Nacional. También debemos contar con la difusión que se hizo de estas publicaciones, y de las ideas contenidas en ellas, en las principales revistas científico-profesionales, y, sobre todo, en los Anales del Instituto Nacional de Previsión.

50 En este sentido se manifestaron Ossorio, Torre Blanco y Pittaluga. ATENEO DE MADRID (1934), pp. 131-132, 186-187 y 240-241. 
también numerosas ventajas y, sobre todo, se estaba convencido de la necesidad de su implantación lo antes posible. Por ello, conocidos los principales motivos de inquietud de la clase médica organizada frente a dicha medida y sabiendo lo importante que era contar con su apoyo ${ }^{51}$, resultaba ineludible intentar vencer sus resistencias. De ahí que, como indicó Sánchez Covisa, éste fuera el propósito principal del Ciclo de Conferencias aquí analizado ${ }^{52}$. Presididos por esta idea, Espinosa, Marcelino Pascua y Torre Blanco recordaron que España había adquirido un compromiso internacional al suscribir, y más tarde ratificar, los dos Convenios de la X Conferencia Internacional del Trabajo (1927), relativos al establecimiento del SOE de los asalariados de la industria y del comercio, de los trabajadores a domicilio y de los domésticos, y de los asalariados de la agricultura ${ }^{53}$. Esta obligación legal, como señaló Espinosa, se extendía también al ámbito nacional y se hallaba reflejada en el artículo 46 de la Constitución ${ }^{54}$. Pero, además, en opinión de Marcelino Pascua y Severino Aznar, era preciso tener en cuenta la fuerza que el SOE había adquirido en la práctica totalidad de los países europeos, así como las demandas y presiones que los obreros estaban haciendo al respecto y la línea política general de nuestro país ${ }^{55}$.

Como vemos, la instauración del SOE se presentaba ante todo como una obligación prácticamente ineludible. Ahora bien, según Espinosa, Marcelino Pascua y Pittaluga, era también un medio adecuado para mejorar la situación sanitaria de nuestro país en un doble aspecto. Por un lado, en cuanto a la población se refería, al ocuparse de la curación y la prevención de la enfermedad de los asegurados; y, por otro, en lo relativo a la Sanidad nacional, dado el carácter modernizador de la Medicina preventiva y de la asistencia sanitaria que se reconocía a dicho elemento de progreso social $^{56}$. Semejantes beneficios se producirían igualmente en el ámbito rural, tal y como apuntaron Ossorio y Ruiz Morote. Además de proporcionar medios de Higiene Pública y de solventar las carencias de especialistas y de infraestructura hospitalaria, el SOE podía constituirse en un preciado instrumento de educación sanitaria y de mejora material del obrero ${ }^{57}$.

Estas ideas concordaban con lo expresado por los autores franceses y alemanes. Así, en opinión de Chauveau, los seguros sociales y, en particular, el SOE, hacían desaparecer la mortalidad elevada y la miseria, ya que, en primer lugar, «en los tres

\footnotetext{
51 Sobre la importancia de contar con el apoyo de los médicos habían llamado la atención Goldman y Grotjahn. GOLDMAN,F. \& GROTJAHN, A. (1928), Les prestations de l'assurance-maladie allemande du point de vue de l'hygiène sociale, Paris, B.I.T, p. 21.

52 ATENEO DE MADRID (1934), p. 6.

53 ATENEO DE MADRID (1934), pp. 33, 59-60, 181 y 306.

54 ATENEO DE MADRID (1934), p. 33. Espinosa se refería concretamente a los artículos 46 y 65 de la Constitución, que recogía en su libro. ESPINOSA FERRÁNDIZ, J. (1933), pp. 179-180.

55 ATENEO DE MADRID (1934), pp. 99-100, y 305-306.

56 ATENEO DE MADRID (1934), pp. 22-26, 60, 90-94 y 248-249.

57 ATENEO DE MADRID (1934), pp. 109-123 y 129-131.
} 
cuartos de los casos, abolen la indigencia, factor importante de enfermedad»; y, en segundo, «suprimen el temor al mañana, y el sentimiento de seguridad así creado es un poderoso factor de salud moral, primer elemento de salud física» ${ }^{58}$. Además, para el citado autor, la Ley sobre los Seguros sociales de 1928, interesaba no sólo a los asegurados, sino a todos los franceses, «por las ventajas más o menos lejanas que [la ley] no dejará de entrañar, tanto en el ámbito de la organización sanitaria del país como desde el punto de vista económico, educativo, moral y social» ${ }^{59}$.

El mismo Liek que, como ya he indicado, denunció los defectos más comunes de los seguros sociales y, en concreto, del SOE, en Alemania, reconoció también a este último algunos beneficios, tanto para los asegurados como para los médicos y el conjunto de la población. Entre sus principales ventajas destacaba su capacidad para evitar el hambre, la miseria y la inquietud que normalmente se asocian al padecimiento de una enfermedad por el cabeza de familia, cuando éste es asalariado. Pero, además, en su opinión, esta institución había hecho posible en Alemania que el tratamiento médico, «comprendiendo los métodos de examen costosos, tales como radiografías, cistoscopias, etc., así como los medicamentos, gafas, distintas prótesis, los baños, etc, $y$, en caso de determinadas afecciones, la asistencia médica o quirúrgica en los hospitales», llegara a esa capa de la población - los asegurados- de un modo gratuito $^{60}$. Como consecuencia de lo anterior se había observado una mejora en la calidad de la atención médica prestada con respecto a la etapa anterior, ya que desde que existía el seguro de enfermedad el enfermo acudía antes, y podía ser tratado más precozmente y de modo más conveniente, razón por la que solía tener mejor pronóstico. La implantación del SOE había supuesto igualmente la introducción de mejoras en la organización e infraestructura sanitaria, mejoras que beneficiaban no sólo al asegurado, sino indirectamente a toda la población. Por otra parte, el diagnóstico precoz de las distintas enfermedades infecciosas - más fácil tras el SOE- permitía el aislamiento de los hogares contagiosos y, con ello, detener la propagación de las enfermedades epidémicas. A su vez, la curación rápida y definitiva de las enfermedades y de las heridas disminuía la pérdida en el rendimiento del trabajo, y aumentaba por tanto la producción total de Alemania ${ }^{61}$.

\footnotetext{
58 Chauveau, C. (1928), Loi sur les assurances sociales. Commentaire juridique, financier et ad ministratif, Paris, Librairie Générale de Droit et Jurisprudence, p. 38.

59 Chauveau, C. (1928), p. 102.

60 LIEK, E. (1929), pp. 35-36.

${ }^{61}$ LIEK, E. (1929), p. 37.
} 
Todas las ventajas que el autor alemán reconocía al SOE desde la perspectiva de la Higiene Social ${ }^{62}$, justificaban el que el Estado y la mayoría de la sociedad sostuvieran y desarrollaran según sus medios esta institución ${ }^{63}$.

\section{EL SEGURO OBLIGATORIO DE ENFERMEDAD, UN INSTRUMENTO PARA MEJORAR LA SITUACIÓN DE LA CLASE MÉDICA}

Justificada la necesidad y conveniencia de instaurar el SOE, restaba otra labor de enorme importancia: la negociación con la clase médica. La inquietud, la preocupación y los recelos debían ser desterrados. Es por eso por lo que tanto el INP como la minoría médica reformista intentaron contestar las objeciones formuladas por los facultativos contra dicha medida. A tal objeto, Marcelino Pascua subrayó, por un lado, su valor para resolver dos de los problemas existentes en esos momentos en España: el de los médicos titulares y el de la plétora médica ${ }^{64} ; \mathrm{y}$, por otro, su capacidad para introducir mejoras en el trabajo diario de los médicos, proporcionar una «remuneración justa y segura» y ampliar el campo de acción médica ${ }^{65}$.

En suma, como había reconocido Liek en el caso de Alemania ${ }^{66}$ y expuso más ampliamente Severino Aznar, la instauración del SOE tendría ventajas de orden económico, profesional y social para los médicos. Las primeras estarían relacionadas con la regularidad de los ingresos, y la posibilidad de que la remuneración del Seguro fuera «más alta y más segura» que la de la Mutualidad y la iguala. A ello habría que añadir también los beneficios económicos derivados del aumento de la zona de intervención del cuerpo médico, por cuanto, por un lado, el Seguro obligaría:

62 Sobre esta cuestión, un interesante texto es el de GoldmAn, F. \& GROTJAHN, A. (1928), pp. 1, 3 y 19-187, que fue realizado con la intención de mostrar el valor del SOE - fundamento, en opinión de los autores, de todo el sistema de Seguros sociales - para responder a las necesidades de la Higiene Social. Con ello se perseguía facilitar la instauración del SOE en los países en los que aún no se había implantado.

${ }^{63}$ LIEK, E. (1929), p. 38. La argumentación esgrimida por Liek en pro del SOE fue recogida por Espinosa. ESPINOSA FERRÁNDIZ, J. (1933), pp. 44-45. A estas ideas de Liek acudieron también los socialistas franceses (CGT) para defender los seguros sociales, cuando, en 1933, se intentaba interrumpir su aplicación. Bulletin ouvrier des assurances sociales, 1, février 1933, p. 4.

${ }^{64}$ Realmente el problema de la plétora médica era común en los demás países de nuestro entorno, y, como puntualizó Torre Blanco, el SOE podía resolver muchos de los problemas que tenía entonces la clase médica, pero, precisamente, no éste. Ésa debía ser una obra de los propios médicos. ATENEO DE MADRID (1934), pp. 74 y 90-100.

65 Ésta era también la opinión de Ruiz Morote. ATENEO DE MADRID (1934), p. 121.

${ }^{66}$ En opinión de Liek, la instauración del SOE resultaba beneficiosa para el médico por cuanto le proporcionaba una remuneración suficiente, facilitaba el establecimiento de los jóvenes, y, sobre todo, procuraba una ocupación constante. De esta manera, el facultativo tenía la posibilidad de acumular observaciones médicas y de aumentar y fijar sus conocimientos. LIEK, E. (1929), p. 37. 
«[...] a todos los beneficiarios a solicitar sus servicios, incluso a los que ahora prescinden de ellos por economía, por dificultad de utilizarlos (...), o por costumbre de acudir al remedio casero, al servicio del intruso, etc.» ${ }^{67}$;

$\mathrm{y}$, por otro,

«[...] estimularía poderosamente a todos los beneficiarios a llamar al médico tan pronto como sientan las primeras manifestaciones de una enfermedad» 68 .

Esa posibilidad de disponer de un número más elevado de pacientes y, por ello, de tener un «mayor campo para sus experiencias y para su observación», así como el hecho de contar con una provisión abundante de medios preventivos y curativos -que caracterizaba en todas partes la implantación del SOE-, se traducirían en una «mayor eficacia para su prestación sanitaria» ${ }^{69}$. Como vemos, para el técnico del INP, a diferencia de lo que opinaba Piga, el Seguro no se acompañaría de un deterioro de la labor desarrollada por el facultativo, sino, muy al contrario, implicaría mejoras en su actividad científico-técnica. De esa manera, aumentaría también el poder y las ventajas del médico, ya que sería «más útil a la sociedad y ésta [tendría] para él mayor estimación ${ }^{70}$. Esto era así, por cuanto,

«[...] al evitar, gracias al Seguro, la enfermedad de la clases obreras, o curarla, si se ha producido, el médico presta a la sociedad el servicio de reducir el dolor y aumentar el rendimiento y la capacidad de trabajo de las grandes masas» ${ }^{71}$.

Como continuó diciendo Aznar, estas ventajas de orden social se derivaban también de los siguientes hechos:

«a) Porque [el SOE] acusa y subraya la enorme importancia que la sociedad da a la función del médico, al hacer depender de él la salud de las grandes masas hasta ahora abandonadas a su solo esfuerzo e iniciativa;

b) Porque le presta así mayor servicio y más clara y conscientemente reconocido;

c) Porque se lo presta con mayor eficacia. Y la sociedad valora, estima y agradece los servicios que una clase le presta según la cantidad, la calidad y perfección de la función que se le presta» 72 .

\footnotetext{
67 ATENEO DE MADRID (1934), p. 323.

68 ATENEO DE MADRID (1934), p. 324.

69 ATENEO DE MADRID (1934), pp. 324-325.

70 ATENEO DE MADRID (1934), p. 327.

71 ATENEO DE MADRID (1934), p. 326.

72 ATENEO DE MADRID (1934), pp. 325-326.
} 
Por todo ello, «el valor social, el papel del médico en la sociedad con el Seguro de Enfermedad sube». De hecho, en su opinión,

«[...] el Seguro lo convierte en magistrado dispensador de derechos y tutor del cumplimiento de deberes. En rigor, de su diagnóstico dependerían las indemnizaciones que los asegurados cobren y la utilización de hospitales, clínicas o sanatorios. Le da el poder de reglamentar la higiene del trabajador y de su familia, de obligar al obrero a suspender el trabajo, y a la Caja a pagarle auxilios médicos, curas, aparatos, sanatorios, etc.» ${ }^{73}$.

Presentado así, el SOE aparecía como un importante instrumento de mejora profesional que permitiría aumentar ostensiblemente el influjo del médico y de la Medicina en la sociedad. Además, como indicó Pittaluga, el SOE era «uno de esos fenómenos comparables entre sí por la magnitud de su importancia social e histórica, y, al propio tiempo, por lo ineluctable de su advenimiento», y, por ello, era preciso aceptarlo ${ }^{74}$.

\section{HACIA LA DEFINICIÓN DEL MODELO DE SEGURO OBLIGATORIO DE ENFERMEDAD APLICABLE EN ESPAÑA}

No obstante, como continuó diciendo el citado médico, la aceptación del SOE debía realizarse con dos condiciones:

«[...] primera, no tener ningún recelo de orden teórico y político en contra de su adopción; y segunda, adaptarlo, aprovechando la experiencia ajena, a las necesidades y a las circunstancias de nuestro país, de su psicología y de su economía, de la viva tradición profesional de nuestros médicos, de la situación demográfica y cultural de nuestro pueblo, en cuanto ha de ser beneficiario del Seguro de Enfermedad» ${ }^{75}$.

De modo que, a tenor de las palabras de Pittaluga que acabo de reproducir, especialmente de lo relativo al segundo requisito a cumplir, parece apropiado pensar que lo que se perseguía era no sólo convencer a los médicos de la necesidad de implantar el SOE, sino también de que éste fuera un modelo concreto: el que se estaba gestando en el seno del INP. Como he adelantado, éste, al igual que había ocurrido en Francia cuando el gobierno comenzó a confeccionar el proyecto de ley sobre los Seguros sociales al término de la Primera Guerra Mundial, era básicamente el modelo alemán. Se trataba de un modelo contributivo, de aportación tripartita, caracterizado por una organización

\footnotetext{
73 ATENEO DE MADRID (1934), p. 326.

74 ATENEO DE MADRID (1934), p. 236.

75 ATENEO DE MADRID (1934), p. 237.
} 
económica y sanitaria —que incluía la asistencia y la Medicina preventiva—, con prestación económica y sanitaria, sin libre elección de médico, administrado por el INP a través de las Cajas colaboradoras, y en el que, como indicaba Pittaluga, los médicos

\footnotetext{
«[...] habrían de intervenir en la organización de los servicios técnicos de las Cajas de Seguro (...) como un técnico sin cuyo dictamen no puede montarse el edificio poderoso de todos los centros de diagnóstico, de tratamiento especializado, de prevención y de sanidad, que dependen de las Cajas. Esta intervención ha de ser continua y decisiva, en relación inmediata con los organismos directivos, con la administración central del Seguro» ${ }^{76}$.
}

Al cuerpo médico se le reservaba también el arbitraje de las divergencias. Sin embargo, este papel que parecía otorgarse a los profesionales de la Medicina en el modelo de SOE que se estaba diseñando en nuestro país no era del gusto de dichos facultativos, que se mostraban deseosos de obtener un mayor protagonismo en el nuevo elemento de protección social. Además, como se había puesto de relieve en la Conferencia Nacional de Seguros de Barcelona de $1922^{77}$, y como había ocurrido en Francia hasta la aprobación de la definitiva Ley sobre los Seguros sociales más acorde a los intereses médicos ${ }^{78}$, la mayoría del colectivo no estaba dispuesta a renunciar a la práctica liberal de la Medicina. Es por eso por lo que no nos debe de extrañar que las Conferencias del Ateneo revelaran como principales puntos de fricción la libertad de elección del facultativo, el secreto profesional, los honorarios y forma de pago, la libertad terapéutica y de prescripción y el control y organización del SOE. En efecto, las ideas que sobre dichos puntos mantenían la clase médica organizada, por un lado, y el INP y la minoría médica reformista, por otro, diferían notablemente. De hecho, como se pondrá de relieve seguidamente, el modelo de SOE que parecía subyacer en el pensamiento del colectivo médico español era básicamente el francés.

76 ATENEO DE MADRID (1934), pp. 244-245.

77. Como hemos indicado anteriormente, los Colegios profesionales y los sindicatos médicos defendieron la práctica liberal. INP (1925), vol. I, pp. 251-294, st. 290-294.

78 La libertad de elección de facultativo y el cobro directo a los pacientes por acto médico fueron las primeras reivindicaciones de los médicos franceses. Con posterioridad, se fueron sumando progresivamente otras cinco, quedando recogidas todas ellas, a finales de 1927 , en la denominada «Charte de la Médecine Libérale». Ésta estaba constituida por los siguientes siete puntos: $1 .^{\circ}$ la libertad de elección de facultativo; $2 .^{\circ}$ el respeto absoluto del secreto profesional; $3 .^{\circ}$ el derecho a percibir honorarios por cualquier enfermo atendido en su domicilio, en el hospital o en cualquier establecimiento; $4 .^{\circ}$ el pago directo por el asegurado sobre la base mínima de las tarifas establecidas por los sindicatos médicos; $5 .^{\circ}$ libertad terapéutica y de prescripción; $6^{\circ}$ control de los enfermos por la Caja; y el de los médicos, por el Sindicato médico y la Comisión médica de arbitraje; y, 7..$^{\circ}$ representación del Sindicato médico en las Comisiones técnicas organizadas por las Cajas. «Le Congrès des Syndicats médicaux de France», La Presse Médicale, 97, (3-12-1927), p. 1488. En torno a estos siete puntos se unificó el sindicalismo médico, y con ello la lucha de la clase médica contra la Ley de Seguros sociales. GuILLAUME, P. (1996), Le rôle social du médecin depuis deux siècles (1800-1945), Paris, A.E.H.S.S., pp. 195-197. 
Así, con respecto al primero de los puntos citados, la libertad de elección del facultativo por el asegurado, Espinosa lo consideraba un problema fundamental, y reconocía que existían en el mundo tres sistemas:

«[...] elección restringida a los médicos empleados de las Cajas, tipo de funcionarismo; elección restringida, pero con libertad de elección dentro de un grupo determinado de médicos. Por último, libertad absoluta de elección: todo médico por el solo hecho de ser médico y estar matriculado puede asistir al asegurado» 79 .

En su opinión, todos eran «buenos y malos», no dependiendo «más que de la sustanciación moral de la clase médica y de los asegurados» ${ }^{80}$, por cuanto,

«[...] en los seguros sociales, el ejercicio médico en la asistencia del enfermo tiene una modalidad especial; el médico se convierte en un verdadero árbitro entre dos intereses: por un lado, los intereses de la Caja de Seguros, (...); y, por otro, el interés individual del obrero» ${ }^{81}$.

Sin embargo, a la vista de lo anterior, y del tipo de ejercicio profesional existente en esos momentos en España, Espinosa veía «muy difícil» que en nuestro país pudiera «haber una libertad absoluta de elección del médico por parte del asegurado» 82 .

Por su parte, el socialista Torre Blanco se mostró también un tanto crítico sobre esta misma cuestión. Este autor consideraba que existía un cierto «confusionismo» entre la clase médica en relación con «la libre elección» de facultativo por el asegurado. La demandaban porque «habían oído que se reclamaba en todas partes», pero realmente no entendían exactamente lo que ello significaba. De hecho, cuando se había puesto en marcha el Seguro de Maternidad, ésa había sido una de las cosas acordadas, pero cuando llegó el momento de aplicarla, los Colegios Médicos habían pretendido realizar ellos mismos la selección de los facultativos ${ }^{83}$. Es por eso por lo que el citado médico se manifestaba partidario de una «libertad de elección restringida», al igual que se hacía en otros países, y como se aconsejaba en una «Recomendación» de Ginebra ${ }^{84}$.

Como acabamos de ver, tanto Espinosa como Torre Blanco eran firmes defensores de una libertad restringida de elección de médico por el asegurado. Esta postura, que se puede entender también como expresión de la sustentada en el seno del INP, no era compartida, sin embargo, por la clase médica española organizada. Ésta, si-

\footnotetext{
79 ATENEO DE MADRID (1934), p. 36.

80 ATENEO DE MADRID (1934), p. 36.

81. ATENEO DE MADRID (1934), pp. 36-37.

82 ATENEO DE MADRID (1934), p. 39.

83 ATENEO DE MADRID (1934), pp. 206-207.

84 ATENEO DE MADRID (1934), p. 208.
} 
guiendo el ejemplo de la francesa ${ }^{85}$, reclamaba, como había hecho en la Conferencia de Barcelona de 1922, la libertad absoluta de elección de facultativo ${ }^{86}$.

Otra de las grandes cuestiones sobre la que, al igual que ocurrió en Francia ${ }^{87}$, se centró el debate fue el secreto profesional. Una vez más las posiciones fueron divergentes. Mientras la clase médica organizada era partidaria del secreto profesional absoluto, desde el INP se juzgaba más conveniente una observación menos estricta. Como indicaba Espinosa,

«[...] el secreto profesional debe cumplirse lo más posible; pero siempre y cuando que de su cumplimiento no pueda derivarse un mal público ni social» ${ }^{88}$.

En este sentido, en su opinión, las condiciones que se daban en esos momentos eran tales que «si ocultaran los médicos los informes no habría manera de hacer una verdadera obra científica» ${ }^{89}, y$, sobre todo, no sería posible organizar el Seguro. De hecho, como el citado médico reconocía, la información,

«[...] en el Seguro de Enfermedad hoy se necesita forzosamente para la estadística, para los cálculos actuariales, para las Cajas de seguros, para conocer el movimiento de las enfermedades de sus asegurados» ${ }^{90}$.

Por ello, desde su posición interesada como técnico sanitario del INP, Espinosa se mostraba contrario al secreto profesional absoluto, defendiendo una observación menos rigurosa. Esta posición coincidía con la mantenida en Alsacia y Lorena ${ }^{91}$, pero difería de la que se había adoptado en el resto de Francia. Allí, el cuerpo médico

85 Como he señalado en la nota 78, ésta fue una de las primeras reivindicaciones de los médicos franceses.

86 En efecto, como indiqué anteriormente, ésta fue una de las principales reivindicaciones de los Colegios profesionales y sindicatos en la Conferencia de Seguros de Barcelona de 1922, aunque no figuró en las conclusiones oficiales de dicha reunión. INP (1925), pp. 290 y 361-363.

$87 \mathrm{El}$ respeto absoluto del secreto profesional fue uno de los puntos que integraban la denominada «Charte de la Médecine Libérale». Véase nota 78.

88 ATENEO DE MADRID (1934), p. 47.

89 ATENEO DE MADRID (1934), p. 48.

90 ATENEO DE MADRID (1934), pp. 47-48.

91 Tal y como indicó Kopp, en Alsacia y Lorena, a diferencia del resto de Francia, la observación del secreto profesional se entendía de un modo menos riguroso. KoPP, Dr. (1924), Lettres du Dr.... sur les assurances sociales, Paris, La Revue médicale, pp. 4 y 6. 
había sido partidario de una posición más estricta, que fue, precisamente, la que se impuso en la Ley francesa sobre los seguros sociales ${ }^{92}$.

Con respecto a los honorarios médicos y a la forma de pago, Torre Blanco advertía de la existencia de dos tendencias: una, defendida por la organización de médicos de Sociedades, que tendía a «manifestarse más en el sentido del funcionarismo, del médico a sueldo fijo»; y otra, la de la Unión de Defensa Médica, que defendía el "pago por tarifa de servicios», al igual que se había hecho ante la implantación del Seguro de Maternidad ${ }^{93}$. Por su parte, los médicos franceses exigieron desde el principio el cobro directo a los pacientes por acto médico ${ }^{94} \mathrm{y}$, a partir de 1927 , reclamaron explícitamente que dicho pago directo por el asegurado se efectuara sobre la base mínima de las tarifas establecidas por los sindicatos médicos ${ }^{95}$. Esta fórmula fue la que figuró finalmente en la Ley de $1930^{96}$.

Otro punto que provocaba la inquietud de la clase médica española, al igual que había pasado anteriormente con la francesa ${ }^{97}$, era la libertad terapéutica y de prescripción. Mientras los facultativos abogaban por una libertad absoluta como la existente en Gran Bretaña o Francia, Espinosa y, por extensión, el INP, parecían partidarios de introducir restricciones. De hecho, en opinión del citado médico, debían quedar excluidos, precisamente, aquellos medicamentos de elevado coste respecto de su calidad terapéutica ${ }^{98}$. Las razones de ello eran fundamentalmente economicistas. Como señalaba Espinosa, los cambios introducidos en el ejercicio de la Medicina y la moderna organización terapéutica habían desplazado poco a poco la receta magistral a favor de la del específico. Consecuencia de lo anterior era el valor comercial, en relación con la propaganda empleada para divulgar estos últimos, que se había añadido a su valor científico y terapéutico. Con ello, se habían multiplicado las posibilidades de cometer

92 ANTONELLI, E. (1930), Guide pratique des assurances sociales. Commentaire et texte complet de la loi du 5 avril 1928, modifiée par la loi du 30 avril 1930, s.l. Payot (Bibliothèque technique).

93 ATENEO DE MADRID (1934), p. 208.

94 De entre la abundante literatura existente sobre esta cuestión, cabe citar: BoudiN, P. (1921), «L'assurance-maladie», La Presse Médicale, 12, (9-2-1921), 198-200, pp. 199-200; P.D. (1921), «Assurance-invalidité-maladie», La Presse Médicale, 4, (12-1-1921), p. 51; y «L'Assurance-Maladie. Proposition de loi ayant pour objet la réorganisation des hôpitaux et l'établissement de l'assurance-maladie et invalidité prématurée», La Presse Médicale, 69, (27-8-1921), pp. 1249-1252.

95 Precisamente, éste era el $4 .^{\circ}$ punto de la denominada «Charte de la Médecine libérale». «Le Congrès des Syndicats médicaux de France», La Presse Médicale, 97, (3-12-1927), p. 1488.

96 ANTONELLI, E. (1930).

97 Entre la abundante literatura relativa a esta cuestión, cabe citar: CONTET, E. (1927a), «À propos des Assurances sociales. Médecine avec tiers payant et prescriptions médicales», La Presse médicale, 94 (23-11-1927), pp. 1435-1436; y CONTET, E. (1927b), «À propos des Assurances sociales. Tiers payant et prescriptions médicales», La Presse médicale, 105 (31-12-1927), p. 1613.

98 En este sentido se había manifestado también Espinosa con anterioridad, véase: ESPINOSA FERRÁNDIZ, J. (1933), p. 147. 
abusos ${ }^{99}$. De ahí que las cajas se mostraran reticentes a destinar parte de su dinero para costear ese valor comercial y, sobre todo, para costear «prescripciones inútiles y excesivamente costosas», siendo éste uno de los problemas que más preocupaban al funcionamiento económico de los seguros de enfermedad ${ }^{100}$. De hecho, como decía Espinosa en el Ateneo, en Ginebra se había dado la voz de alarma, insistiendo en que

«[...] los seguros sociales no pueden seguir funcionando si no se hace una revisión total para facilitar al obrero una prestación económica que esté al alcance de sus medios, porque el seguro va abajo y no puede seguir atendiendo a las prestaciones terapéuticas actuales; que no queremos discutir desde el punto de vista de su eficacia terapéutica, sino que queremos que en todo aquello que se prescriba esté su eficacia en relación con su precio. Porque no es posible que a través de los seguros sociales, y con el dinero del obrero, se estén manteniendo todos los periódicos de la nación a través de las hojas de propaganda de los productos farmacéuticos. Para seguir haciendo esta propaganda tienen que sacarlo de los específicos, que el obrero paga»101.

A la vista de estas recomendaciones y de lo ocurrido en Francia, en donde se acababa de limitar el gasto de prescripciones farmacológicas por enfermedad ${ }^{102}$, Espinosa se ratificaba en la idea de restringir la libertad terapéutica y de prescripción.

El último tema, y quizá uno de los más importantes, sobre el que se centraron las intervenciones de todos los ponentes fue el relativo al control y organización del $S O E^{103}$. Si, como he adelantado, el INP proponía que dicho Instituto se encargara de la organización del SOE y de su administración a través de las Cajas colaboradoras, la clase médica organizada ofrecía otras alternativas que, como veremos, se caracterizaban porque el control, la administración y la organización de la parte sanitaria del SOE recaerían directamente en los médicos. Así, en el ámbito rural se detectaban dos posturas parcialmente coincidentes. Por un lado, la defendida por el presidente del Colegio de Médicos de Cáceres, Ruiz Morote, que intentaba compaginar el deseo de la profesión médica de asumir íntegramente la asistencia sanitaria curativa y preventiva rural con las dificultades para materializar dicho deseo en esos momentos ${ }^{104}$. Es por eso por lo que este facultativo aceptaba el valor parcial de la iguala para solucionar el problema de la Medicina rural, y admitía el SOE — concebido como se estaba haciendo desde el INP - únicamente como un solución transitoria hasta que la clase médica estuviera en situación de poder reivindicar que se le entregara «de lleno todo

\footnotetext{
99 ESPINOSA FERRÁNDIZ, J. (1933), pp. 143-144.

100 ESPINOSA FERRÁNDIZ, J. (1933), p. 145.

101 ATENEO DE MADRID (1934), pp. 49-50.

102 ESPINOSA FERRÁNDIZ, J. (1933), p. 146.

103 Sobre la importancia y trascendencia que adquirió esta cuestión a partir del 25 de diciembre de 1933, véase: PORRAS GALLO, M. ${ }^{a}$ I. (1998b).

104 ATENEO DE MADRID (1934), pp. 114-119.
} 
el servicio médico creado» ${ }^{105}$. La otra postura era la de Antonio Ossorio, presidente de la Asociación oficial de Inspectores municipales de Sanidad y Médicos Titulares de España. Este profesional, y los que él representaba, creían difícil la instauración del SOE en el medio rural, y juzgaban prioritaria «la implantación de la iguala reglamentada», por concebirla como «una modalidad del Seguro», capaz de resolver «el problema de la asistencia» ${ }^{106}$. La modalidad de iguala defendida por Ossorio era la adaptación que estaba estudiando el Consejo General de Colegios de Médicos. Con esa fórmula, cada Colegio de Médicos se encargaría de la organización y control del nuevo tipo de iguala, a través del cual se proporcionaría la asistencia médica del SOE. Las otras prestaciones del seguro correrían a cargo de las Cajas de seguros o Mutualidades de Socorros Mutuos ${ }^{107}$. De esta manera, recaía directamente sobre los médicos la organización, administración y control de la prestación sanitaria del seguro, quedando eliminado el intermediario entre el enfermo y el facultativo.

La idea de que la iguala «debidamente reformada» podía servir de base «para la aplicación de prestaciones sanitarias en el medio rural» dentro del SOE, era defendida también por Torre Blanco, Severino Aznar y, en menor medida, por Pittaluga, si bien su concepción del nuevo modelo de iguala difería de lo postulado por los médicos titulares con el beneplácito de los Colegios Médicos. Tanto Aznar como Pittaluga $\mathrm{y}$, especialmente, Torre Blanco criticaban la tendencia «en los médicos, en las entidades médicas, Sindicatos, Colegios, a organizar los Seguros Sociales» ${ }^{108}$, siendo partidarios de la intervención de los técnicos del INP en la organización y administración del SOE.

A su vez, en cuanto al medio urbano se refería, cabe decir que, tal y como denunció Torre Blanco, en enero de 1934 se había constituido en Madrid una organización de médicos denominada Unión de Defensa Médica ${ }^{109}$. Esta entidad tenía la pretensión de «centralizar en una sola todas las Sociedades de médico, botica y entierro» que existían, «bajo la forma de Cooperativa, dirigida, administrada y controlada por los mismos médicos» ${ }^{110}$. Con ello se perseguía «formar un sistema de prestaciones sanitarias que poder ofrecer al Seguro de Enfermedad, y tener el monopolio de la asistencia médica» ${ }^{111}$. La citada institución se ocuparía de los enfermos de clase obrera y clase media, dejando los pobres a cargo de las Beneficencias oficiales y privadas y los pudientes para el ejercicio libre. La creación de esta Cooperativa de Asistencia Médica se pre-

\footnotetext{
105 ATENEO DE MADRID (1934), p. 123.

106 ATENEO DE MADRID (1934), p. 149.

107 ATENEO DE MADRID (1934), p. 143.

108 ATENEO DE MADRID (1934), p. 211.

109 TORRE BlanCO, J. (1934), «Sobre la llamada 'Unión de Defensa Médica'», El Heraldo de Madrid, 1 de enero de 1934, p. 10.

110 MUT, J. (1934), «U.D.M. Cooperativa de Asistencia Médica», La Medicina Ibera, 845, LIII-LV, p. LIII.

111 ATENEO DE MADRID (1934), p. 213.
} 
sentaba como una tarea verdaderamente urgente, mostrándose convencidos de «que de no realizar nosotros [los médicos] esta magna obra, el Estado, en plazo brevísimo, establecería el Seguro de enfermedad». De producirse esa situación, continuaban diciendo, «si bien desaparecían las sociedades, el médico solamente [cambiaría] de empresa», que, «como todas, [sería] ajena a los intereses de la clase» ${ }^{112}$.

A la vista de lo anterior, parece evidente que, tanto para el medio rural como para el urbano, existían alternativas a la propuesta de SOE que se estaba gestando en el INP, que diferían notablemente en lo relativo a la organización, administración y control de la prestación sanitaria del Seguro de Enfermedad. Esta postura de la clase médica española difiere de la mantenida por los facultativos franceses. En efecto, estos últimos reclamaron que el control de los médicos fuera realizado por los Sindicatos médicos y la Comisión médica de arbitraje, y que dichos sindicatos contaran con representación en las Comisiones técnicas organizadas por las Cajas de Segu$\operatorname{ros}^{113}$, pero no estuvieron dispuestos a asumir la organización y administración de las distintas medidas de Medicina Social, entre ellas los Seguros Sociales. Tan sólo Lafontaine, secretario general de l'Union des syndicats de médicaux de France, y Longlet se mostraron partidarios del desarrollo de la Medicina social, siempre y cuando éste se realizara bajo el control de los sindicatos médicos ${ }^{114}$.

Como acabamos de ver, las ideas de la clase médica organizada española respecto a la libertad de elección del facultativo, el secreto profesional, los honorarios y formas de pago, la libertad terapéutica y de prescripción y el control y organización del SOE, coincidían en buena medida con las de sus colegas franceses. De modo que, como adelanté, parece confirmarse que el modelo de SOE que subyacía en el pensamiento del colectivo médico español era básicamente el francés que, tras la aprobación de la Ley del 5 de abril de 1928, modificada por la del 30 de abril de 1930, había comenzado a aplicarse definitivamente el 1 de julio de $1930^{115}$.

\section{CONCLUSIONES}

A través de las páginas precedentes hemos podido ver cómo en 1934, al inicio del bienio negro republicano, el SOE cobró renovada actualidad con motivo del traspaso

112 ROCABERT, R. y BERITENS, J. (1934), «Sobre anulación de Sociedades médico-farmacéuticas y de enterramiento", Boletín del Colegio Oficial de Médicos de Madrid, 139, 22-25, p. 25.

113 Como se ha visto en la nota 78, éstas fueron dos de las siete reivindicaciones de los médicos franceses incluidas en la denominada «Charte de la Médecine Libérale».

114 MERRIEN, F.-X. (1988), «La loi sur les pensions et le conflit avec le corps médical (1919-1921): anticipation et genèse d'une rélation socio-politique». En: Colloque sur l'histoire de la sécurité sociale(Lyon, 1987), Paris, A.E.H.S.S., 375-388, pp. 386-388. Mayor información sobre esta cuestión, puede encontrarse en: GuILLAUME, P. (1996), pp. 168-172 y 178.

115 En el caso del SOE su aplicación se retrasó hasta septiembre de 1930. 
de Sanidad al Ministerio de Trabajo. Este traspaso y la inclusión de Sanidad y Previsión en una misma subsecretaría, unido al protagonismo alcanzado por la clase médica organizada en el nuevo Gobierno, se relacionó con la introducción de posibles cambios en la organización, aplicación y control del SOE. Esto produjo la inquietud de los médicos y, sobre todo, del INP, desencadenándose un intenso debate, que tuvo como uno de sus principales foros de expresión el Ateneo de Madrid. La citada institución consagró las sesiones del nuevo curso al Seguro de enfermedad con la intención de vencer las resistencias de los médicos frente al SOE y, más concretamente, respecto al modelo que se estaba gestando en el INP. De ahí que más de la mitad de los ponentes estuvieran comprometidos en mayor o menor medida en la defensa del tipo de seguro diseñado desde el citado Instituto, y se contara también con los representantes de la clase médica organizada.

Como se ha puesto de relieve, de cara a lograr el citado objetivo de crear un ambiente favorable al SOE, su implantación se presentó como una obligación -nacional e internacional-, pero también como una necesidad que ofrecía numerosas ventajas tanto para mejorar nuestra situación sanitaria como la de la clase médica. Para ello, al igual que para señalar sus principales inconvenientes, los médicos españoles y los técnicos del INP se sirvieron de los argumentos utilizados por los colegas de otros países, especialmente franceses y alemanes. Junto a ellos incorporaron elementos específicos relacionados con nuestra coyuntura y estructura socio-política y sociosanitaria. A su vez, cuando se trató de exponer qué modelo de SOE se aceptaría, partiendo del modelo alemán - defendido desde el INP-, y teniendo presente el francés - recientemente instaurado—, la clase médica española se mostró partidaria de una Medicina liberal e hizo suyas prácticamente las mismas reivindicaciones de los franceses, aunque con una peculiaridad: deseaban ser los encargados de la organización, administración y control de la prestación sanitaria del SOE tanto en el ámbito rural como urbano. En el primer caso, el procedimiento propuesto era la iguala modificada conforme a lo diseñado por los Colegios de médicos; y en el segundo, se trataba de constituir una Cooperativa de Asistencia Médica, a través de la cual se prestaría la asistencia sanitaria. 